\title{
Becoming a Patient-Centered Medical Home: A 9-Year Transition for a Network of Federally Qualified Health Centers
}

\author{
Neil S. Calman, $M D^{1,2}$ \\ Diane Hauser, MPA ${ }^{1,2}$ \\ Linda Weiss, $P b D^{3}$ \\ Eve Waltermaurer, $P b D^{4}$ \\ Elizabeth Molina-Ortiz, MD, MPH \\ Tongtan Chantarat, $\mathrm{MPH}^{3}$ \\ Anne Bozack, MPH \\ 'The Institute for Family Health, New York, \\ New York \\ ${ }^{2}$ Department of Family Medicine and Com- \\ munity Health, Icahn School of Medicine at \\ Mount Sinai, Mount Sinai Hospital, New \\ York, New York \\ ${ }^{3}$ The New York Academy of Medicine, \\ New York, New York \\ ${ }^{4}$ State University of New York at New \\ Paltz, New Paltz, New York
}

Conflicts of interest: authors report none.

\section{CORRESPONDING AUTHOR}

Diane Hauser, MPA

The Institute for Family Health

Department of Family Medicine and Community Health

Icahn School of Medicine at Mount Sinai 16 E 16th St

New York, NY 10003

dhauser@institute2000.org

\begin{abstract}
PURPOSE The patient-centered medical home (PCMH) model has great potential for optimizing the care of chronically ill patients, yet there is much to be learned about various implementations of this model and their impact on patient care processes and outcomes.
\end{abstract}

METHODS We examined changes in patterns of health care use in a network of Federally Qualified Health Centers throughout a 9-year period of practice transformation that included recognition of all centers by the National Committee for Quality Assurance (NCQA) as Level 3 PCMH practices. We analyzed deidentified data from electronic health records for the period 2003 to 2011 to identify patterns of service use for all 4,595 patients with diabetes. We also examined a subsample of 545 patients who were in care throughout the study period to track improvement in glycated hemoglobin levels as a clinical measure over time.

RESULTS Through the transition to a PCMH, the mean number of encounters with outreach, diabetes educators, and psychosocial services increased for all diabetic patients; virtually all patients had visits with a primary care clinician, but the mean number of visits decreased slightly. Among patients in the subsample, mean annual levels of glycated hemoglobin decreased steadily during the 9-year study period, mainly driven by a reduction in patients having baseline levels exceeding $9 \%$.

CONCLUSIONS This retrospective study conducted in a real-world setting using electronic health record data demonstrates a shift in resource use by diabetic patients from the primary care clinician to other members of the care team. The findings suggest that $\mathrm{PCMH}$ implementation has the potential to alter processes of care and improve outcomes of care, especially among those with higher disease burden.

Ann Fam Med 2013;11:S68-S73. doi:10.1370/afm.1547.

\section{INTRODUCTION}

7 he patient-centered medical home (PCMH) model has great potential for optimizing the care of chronically ill patients. Key characteristics of a PCMH include a personal physician, team-based care, whole-person orientation, coordinated and integrated care, attention to quality and safety, enhanced access to care, and rational payment methods. ${ }^{1,2}$ PCMH incorporates the use of advanced health information technology to achieve many of these practice changes-and to support optimal care, enhance communication and patient education, facilitate coordination of services, and measure performance.

Although there is some evidence that having a regular source of care, one aspect of the PCMH model, results in more timely receipt of preventive services, ${ }^{3.5}$ overall better health, ${ }^{3,5}$ better glycated hemoglobin $\left(\mathrm{HbA}_{1 \mathrm{c}}\right)$ control for those with diabetes, ${ }^{6}$ and reductions in emergency 
department use, ${ }^{7}$ there is much to be learned about how various adoptions of this model work and the extent to which they result in better patient outcomes.

The primary goals of our study were (1) to describe the adoption of the PCMH model within a Federally Qualified Health Center (FQHC) network as it relates to the care of diabetic patients and (2) to examine service use among all diabetic patients accessing care as the care model changed to include elements of the PCMH model. In addition, using a subsample of patients with diabetes who accessed care at the study sites throughout PCMH implementation, we assessed changes in $\mathrm{HbA}_{1 \mathrm{c}}$ as the PCMH model was adopted. Because the care model called for targeting services to patients at highest risk of complications, defined as those with $\mathrm{HbA}_{1 \mathrm{c}}$ values greater than $9 \%$, we compared service use and mean levels for cohorts of patients with beginning values above and below this threshold. These analyses reflect a real-world implementation of the PCMH model and show its impact on selected process changes in patients with diabetes.

\section{METHODS}

\section{The Setting}

Our FQHC network in New York State, the Institute for Family Health (the Institute), began a process of practice redesign in 2002 with the implementation of an electronic health record (EHR). Additional practice innovations were implemented in the subsequent 9-year period. The Institute achieved Level $3 \mathrm{PCMH}$ recognition from the National Committee for Quality Assurance (NCQA) in 2009, and again in 2012 with the enhanced standards, across its network of 17 sites, which are spread across 130 miles from lower Manhattan in New York City to Ulster County in the Hudson Valley of New York State. ${ }^{8}$

All sites are located in medically underserved areas, with urban areas designated either for their neighborhoods or for the needy populations they serve, and rural sites designated based on a dearth of primary care clinicians. Sites range in size from 2 primary care clinicians ( 2 urban practices and 1 rural practice) to more than 20 such clinicians ( 2 urban practices) with most practices having between 4 and 8 . All practices operate on a family medicine model, and the vast majority of primary care clinicians are trained in family medicine. All practices have on-site psychosocial services that range from a social worker in smaller sites to fully licensed outpatient mental health facilities in several larger sites. Four sites have dental services. Two of the sites are primary teaching facilities for community-based family medicine residency program, and all sites provide clinical training for students from a variety of health professions schools.
The sites are operated through a central administrative structure that includes a Senior Vice President for Medical Affairs (a family physician), Clinical Services (a registered nurse with a masters in business administration), and Psychosocial Services and Community Affairs (a social worker with a doctorate in social work) who have worked together for more than 10 years. Together, they are responsible for the oversight of all clinical services and teaching programs, and they share responsibility for making decisions for changes in care processes.

\section{PCMH Implementation}

The Institute implemented a systemwide, integrated EHR and practice management system (Epic Systems) in 2002 and adopted other key elements of the PCMH model in the ensuing years. $\mathrm{PCMH}$ recognition was advanced by a team appointed by the president and chief executive officer of the Institute and led by its Senior Vice President for Clinical Services. From the outset, a target date was set by which all sites were to meet the NCQA standards at a level adequate to achieve Level 3 recognition, and a timeline was established that led to that outcome. The team met weekly as the PCMH model was being developed to report on progress and address obstacles. They were supported by health information technology staff who could program decision supports, registry changes, and workflow changes into the network's EHR system.

Central elements of the transformation to the PCMH included the following:

- Modifications to practice workflows (eg, shifting certain screening and educational responsibilities to nurses), which enabled staff to work at optimal efficiency and effectiveness individually and as a team;

- Expansion of on-site open-access psychosocial services;

- Development of registries and report-based outreach to provide population-based care for patients, with a focus on those at highest risk for poor outcomes;

- Implementation of a custom-designed visit summary that provides patients with key health information from their records and the day's visit, including treatment goals; and

- Implementation of an interactive patient portal.

A set of PCMH practice changes specifically focused on the care of patients with diabetes. These changes included the following:

- Group visits in English and Spanish to promote patient education and peer support (2007)i

- Appointment of a family physician as the Diabetes Medical Director, responsible for overseeing 
activities at all sites related to the care of patients with diabetes and prediabetes (2008);

- Creation of a diabetes registry and a quality reporting tool aligned with NCQA diabetes care standards that primary care clinicians and site medical directors can review in the aggregate, by site, by individual clinician panel, and by racial and ethnic groupings to identify potential disparities (2008); this tool was available from within the EHR, and a reminder was sent to each clinician to check their registry weekly; registry review by each clinician was recorded centrally, and those who did not check their registry were sent additional notes of encouragement;

- Addition of certified diabetes educators (CDEs) to the care team (2008), an effort supported by a private foundation grant;

- Implementation of EHR-based clinical decision supports for each NCQA diabetes measure (2008);

- Outreach to patients with clinical measures outside of recommended values and missed or overdue appointments, with priority given to patients with $\mathrm{HbA}_{1 \mathrm{c}}$ values exceeding 9\% (2008); outreach was accomplished in 3 ways: (1) a central telephonic outreach team worked with lists from the diabetes registry provided by the lead diabetes educator $_{i}(2)$ lists were also sent to the receptionists at health center sites to provide outreach to patients who had missed appointments and/or had been lost to follow-up; and (3) diabetes educators made calls to patients identified to be at highest risk because of elevated $\mathrm{HbA}_{1 \mathrm{c}}$ or blood pressure values and conducted outreach to those who failed to keep follow-up appointments with them after their initial evaluation;

- On-site testing of $\mathrm{HbA}_{1 \mathrm{c}}$ levels (2008), which enabled rapid changes in treatment when warranted, as clinicians had the information immediately available to them; and

- Addition of diabetes care managers to the care team with support from a private foundation grant (2010).

\section{Overview of Study}

The study period was calendar years 2003 to 2011, which includes years before PCMH transformation (2003-2007) and years during the introduction and expansion of this model (2008-2011). We used deidentified clinical, administrative, and demographic data documented in the EHR in the course of care for all analyses described here. We included in the analysis only the 8 sites in New York City that were part of the Institute's network and captured data in the EHR throughout the 9 -year study period. We excluded 9 sites that were added to the network during the study period, including all sites in the Hudson Valley.

\section{Sample and Subsample}

We based analyses of service use on 4,595 patients who had a documented diagnosis of diabetes and at least 1 office visit during the study period, and who were aged 18 years or older at the time of that visit. Patients receiving only psychosocial services, screening, or influenza vaccines, or some combination thereof, were excluded as they were not receiving primary care services at an Institute center. To analyze annual service use in the sample population, we included use data for individual patients for each year they accessed any service at a study site. This sample was stratified into those with initial $\mathrm{HbA}_{1 \mathrm{c}}$ values of $9 \%$ or lower vs greater than $9 \%$ in each year to explore the targeting of services to patients at highest risk for diabetes complications.

We used a subsample of 545 patients from the sample population described above in the analysis of mean $\mathrm{HbA}_{1 \mathrm{c}}$ levels. This subsample included patients with at least 1 documented $\mathrm{HbA}_{1 \mathrm{c}}$ value in each of 3 time periods: a baseline period (2003-2004), a midpoint period (2005-2007), and the PCMH transformation period (2008-2011).

\section{Service Use}

For the sample population, we included all encounters between 2003 and 2011 in the analytic data set. Office visits are routinely coded to identify encounter type. For the purpose of analysis, we grouped encounters into categories most relevant to diabetes care within a PCMH model: (1) outreach (by telephone or letter) (2) diabetes care (visits with a diabetes educator), (3) psychosocial care (visits with a psychologist, psychiatrist, or social worker), and (4) primary care. We considered all office visits with a medical professional (medical doctor, nurse practitioner, or physician assistant) that were not for psychosocial care to be primary care visits.

\section{Clinical Changes}

We used $\mathrm{HbA}_{1 \mathrm{c}}$ values to assess clinical change, as this value is a key indicator of diabetes control. Within the subsample of patients, we calculated annual mean $\mathrm{HbA}_{1 \mathrm{c}}$ values separately for the subsample overall and for patients with initial values greater than $9 \%$ and with initial values of $9 \%$ or lower.

\section{Analytic Methods}

For the sample population, we used descriptive statistics (means and proportions) to characterize service use for all patients accessing care at a study site each year between 2003 and 2011. For the subsample of 
patients, we performed descriptive analyses using mean $\mathrm{HbA}_{1 \mathrm{c}}$ levels each year between 2003 and 2011.

\section{RESULTS}

\section{Population Characteristics}

Consistent with the Institute's overall patient population, our sample of patients with diabetes was predominantly female $(57.8 \%)$. Nearly one-half identified themselves as Hispanic, roughly one-third were African American, and more than one-quarter identified themselves as "other," including multiracial. One-third of patients were insured by Medicaid, roughly one-quarter were insured by Medicare, and another one-quarter were insured by a private insurer. The mean age at diagnosis of diabetes or entry into the practice with an existing diagnosis was approximately 53 years. Nearly $30 \%$ of patients had an $\mathrm{HbA}_{1 \mathrm{c}}$ value greater than $9 \%$ on entry into care at the Institute. More than one-half of the patients were obese, and roughly two-thirds had a diagnosis of hypertension or hyperlipidemia. Thirty percent of patients had a diagnosis of depression.

\section{Service Use of Sample Population}

Annual use of diabetes-related PCMH services is shown in Table 1 , stratified by baseline $\mathrm{HbA}_{1 \mathrm{c}}$ values. We used $\mathrm{HbA}_{1 \mathrm{c}}$ values of $9 \%$ as a cut point because of its clinical importance for the management of diabetes and for the assessment of our efforts at focusing intensive care management on those at highest risk of poor outcomes. ${ }^{9}$

Although roughly $60 \%$ of the patients with diabetes received outreach in the form of a letter or telephone call from their primary practice at the beginning of the study period, this type of outreach was nearly universal by 2011. With the addition of CDEs to the model later in the transformation period, a higher proportion of patients with $\mathrm{HbA}_{1 \mathrm{c}}$ values greater than 9\% had a CDE visit during the 2008 to 2011 period as compared with those having lower values, indicating success at directing resources to those at highest risk.

Patients accessed psychosocial services at varying rates throughout the study period, with the highest rates occurring in the most recent study year. Annual rates of primary care visits were high throughout the study period, with nearly all patients accessing these

\begin{tabular}{|c|c|c|c|c|c|c|c|c|c|}
\hline \multirow[b]{2}{*}{$\begin{array}{l}\text { Group } \\
\text { and Year }\end{array}$} & \multirow[b]{2}{*}{$\begin{array}{l}\text { Patients, } \\
\text { No. }\end{array}$} & \multicolumn{2}{|c|}{ Outreach Services $^{a}$} & \multicolumn{2}{|c|}{$\begin{array}{c}\text { Diabetes Education } \\
\text { Services }^{\mathrm{b}}\end{array}$} & \multicolumn{2}{|c|}{$\begin{array}{l}\text { Psychosocial Care } \\
\text { Services }^{c}\end{array}$} & \multicolumn{2}{|c|}{$\begin{array}{l}\text { Primary Care } \\
\text { Services }^{\mathrm{d}}\end{array}$} \\
\hline & & $\begin{array}{c}\text { Received, } \\
\%\end{array}$ & $\begin{array}{c}\text { Mean (SD), } \\
\text { No.e }\end{array}$ & $\begin{array}{c}\text { Received, } \\
\%\end{array}$ & $\begin{array}{c}\text { Mean (SD), } \\
\text { No. }^{e}\end{array}$ & $\begin{array}{c}\text { Received, } \\
\%\end{array}$ & $\begin{array}{c}\text { Mean (SD), } \\
\text { No. }^{e}\end{array}$ & $\begin{array}{c}\text { Received, } \\
\%\end{array}$ & $\begin{array}{c}\text { Mean (SD), } \\
\text { No. }^{\text {e }}\end{array}$ \\
\hline \multicolumn{10}{|l|}{$\mathrm{HbA}_{1 \mathrm{c}} \leq 9 \%^{\mathrm{f}}$} \\
\hline 2003 & 398 & 59.0 & $2.1(3.2)$ & 0.0 & $0.0(0.0)$ & 9.0 & $0.2(1.1)$ & 99.7 & $5.4(3.2)$ \\
\hline 2004 & 696 & 74.4 & $3.2(4.4)$ & 0.0 & $0.0(0.0)$ & 20.7 & $0.9(3.0)$ & 99.7 & $5.8(3.8)$ \\
\hline 2005 & 914 & 78.2 & $3.2(3.9)$ & 0.0 & $0.0(0.0)$ & 26.6 & $1.0(4.0)$ & 99.8 & $5.8(3.6)$ \\
\hline 2006 & 1,031 & 81.5 & $3.2(3.9)$ & 0.0 & $0.0(0.0)$ & 25.5 & $0.9(2.6)$ & 99.3 & $5.9(3.7)$ \\
\hline 2007 & 1,085 & 70.8 & $3.0(3.3)$ & 0.0 & $0.0(0.0)$ & 17.5 & $0.7(2.6)$ & 98.8 & $5.1(3.4)$ \\
\hline 2008 & 1,251 & 86.4 & $3.4(3.3)$ & 4.1 & $0.1(0.4)$ & 18.9 & $0.7(2.4)$ & 98.4 & $5.5(3.8)$ \\
\hline 2009 & 1,512 & 82.6 & $3.4(3.6)$ & 21.1 & $0.5(1.4)$ & 19.4 & $0.7(2.9)$ & 98.1 & $4.8(3.6)$ \\
\hline 2010 & 1,731 & 90.1 & $4.2(4.1)$ & 19.4 & $0.5(1.2)$ & 19.2 & $0.9(3.3)$ & 98.3 & $4.5(3.3)$ \\
\hline 2011 & 2,057 & 95.3 & $5.9(5.6)$ & 53.3 & $1.3(2.2)$ & 27.4 & $1.0(3.4)$ & 99.4 & $4.7(3.2)$ \\
\hline \multicolumn{10}{|l|}{$\mathrm{HbA}_{\mathrm{lc}}>9 \%{ }^{\mathrm{f}}$} \\
\hline 2003 & 161 & 60.2 & $1.8(2.7)$ & 0.0 & $0.0(0.0)$ & 11.2 & $0.4(2.4)$ & 99.4 & $5.9(4.1)$ \\
\hline 2004 & 234 & 73.9 & $2.4(3.2)$ & 0.0 & $0.0(0.0)$ & 18.4 & $0.7(3.0)$ & 100.0 & $5.7(3.9)$ \\
\hline 2005 & 307 & 78.2 & $2.6(3.0)$ & 0.0 & $0.0(0.0)$ & 25.1 & $0.9(4.0)$ & 99.7 & $5.5(4.1)$ \\
\hline 2006 & 321 & 72.3 & $2.5(2.8)$ & 0.0 & $0.0(0.0)$ & 25.2 & $0.5(1.8)$ & 99.1 & $5.3(3.4)$ \\
\hline 2007 & 295 & 87.8 & $3.2(3.3)$ & 0.0 & $0.0(0.0)$ & 17.6 & $0.6(2.4)$ & 97.6 & $4.8(3.6)$ \\
\hline 2008 & 369 & 93.8 & $4.0(3.4)$ & 6.2 & $0.1(0.4)$ & 22.5 & $0.7(2.6)$ & 96.7 & $5.0(3.8)$ \\
\hline 2009 & 425 & 96.0 & $6.3(5.2)$ & 40.2 & $0.9(1.8)$ & 24.9 & $0.8(2.8)$ & 97.2 & $4.6(3.8)$ \\
\hline 2010 & 447 & 95.3 & $6.1(4.6)$ & 39.6 & $1.0(1.7)$ & 22.6 & $1.0(3.6)$ & 98.2 & $4.1(3.2)$ \\
\hline 2011 & 551 & 98.5 & $8.7(7.3)$ & 77.8 & $2.6(3.3)$ & 35.3 & $1.2(3.9)$ & 99.5 & $4.3(3.2)$ \\
\hline \multicolumn{10}{|c|}{$\mathrm{HbA}_{\mathrm{IC}}=$ glycated hemoglobin; $\mathrm{PCMH}=$ patient-centered medical home. } \\
\hline $\begin{array}{l}\text { a Outreach incl } \\
\text { b Diabetes edu } \\
\text { ' Psychosocial } \\
\text { d Primary care } \\
\text { e Mean and SD } \\
{ }^{f} \text { First } \mathrm{HbA}_{1 \mathrm{c}} \mathrm{do}\end{array}$ & $\begin{array}{l}\text { des (1) telephon } \\
\text { tion includes vi } \\
\text { re includes offic } \\
\text { cludes all office } \\
\text { er patient base }\end{array}$ & $\begin{array}{l}\text { nd (2) letter. } \\
\text { with a certifie } \\
\text { isits or encoun } \\
\text { sits not include } \\
\text { n patients with }\end{array}$ & $\begin{array}{l}\text { diabetes educato } \\
\text { ers with (1) psych } \\
\text { I in diabetes care } \\
\text { at least } 1 \text { visit. }\end{array}$ & $\begin{array}{l}\text { r. } \\
\text { atry, (2) psych } \\
\text { and psychosoci }\end{array}$ & $\begin{array}{l}\text { ogy, and/or (3) s } \\
\text { I care. }\end{array}$ & cial worker. & & & \\
\hline
\end{tabular}


Figure 1. Mean $\mathrm{HbA}_{1 \mathrm{c}}$ values for patients seen throughout the 9-year practice transformation to a PCMH.

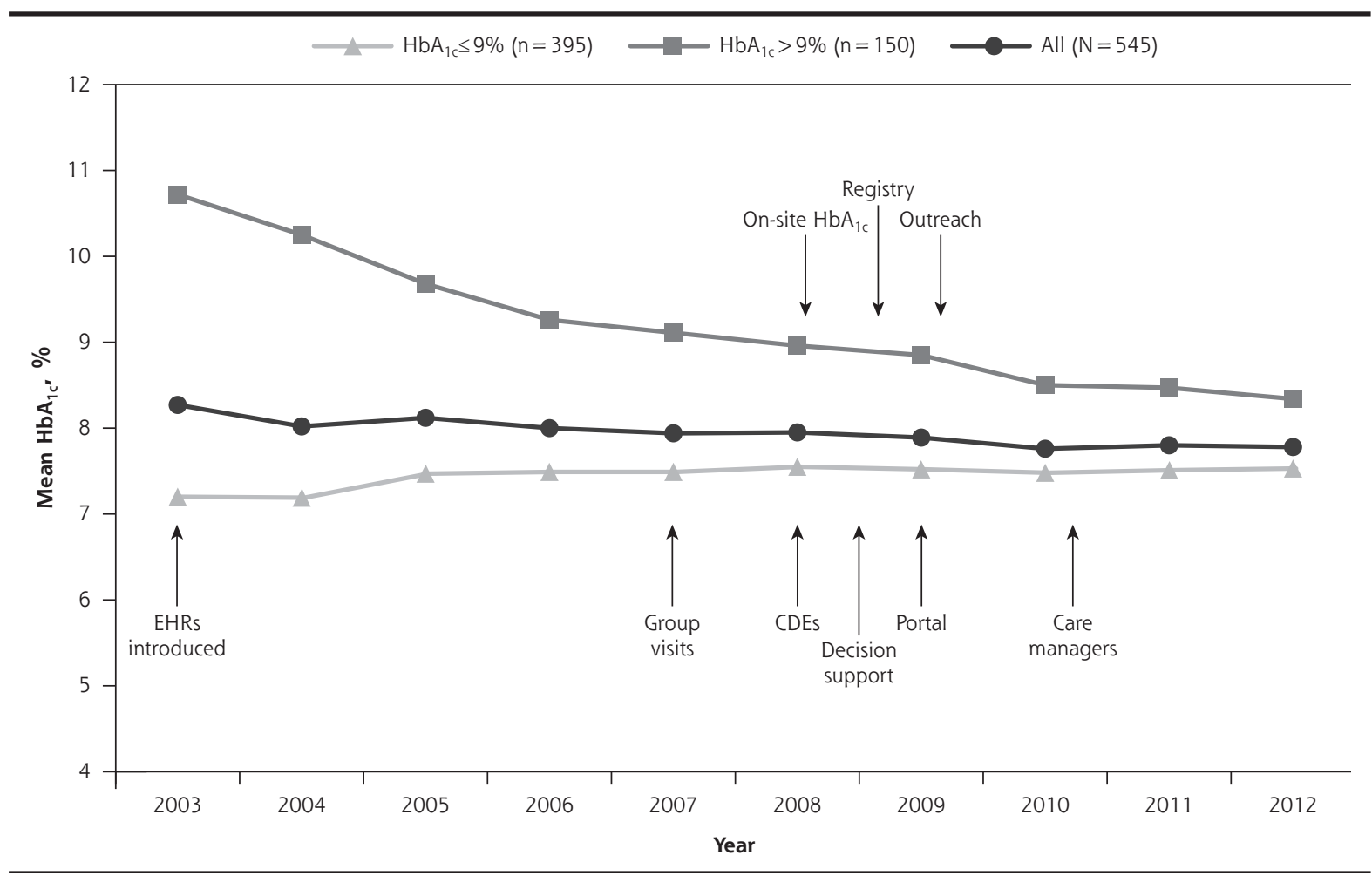

$\mathrm{CDE}=$ certified diabetes educator; $\mathrm{EHR}=$ electronic health record; $\mathrm{HbA}_{\mathrm{lc}}=$ glycated hemoglobin .

services by 2011. An increasing proportion of diabetic patients accessed a wide range of services, with a rise in the mean number of services in each category analyzed, while the total number of patients with diabetes continued to increase. The marked exception was the mean number of primary care visits for patients with initial $\mathrm{HbA}_{1 \mathrm{c}}$ values greater than $9 \%$, which decreased while numbers of other types of encounters increased.

\section{Clinical Change for the Subsample}

Figure 1 shows the annual mean $\mathrm{HbA}_{1 \mathrm{c}}$ values for the subsample of patients who had values during each of 3 periods as described above. Among patients whose $\mathrm{HbA}_{1 \mathrm{c}}$ values at baseline were greater than $9 \%$, there was a steady reduction in mean annual levels over time, from approximately $10.72 \%$ to $8.34 \%$. Among patients whose $\mathrm{HbA}_{1 \mathrm{c}}$ values at baseline were $9 \%$ or lower, mean annual levels showed a slight upward trend.

\section{DISCUSSION}

We analyzed a PCMH transformation in a real-world FQHC network setting with a population of diverse, mostly low income patients and found changes in care processes while suggesting improvement in diabetes control. The observed trends in health care encounters demonstrate patients' increased exposure to a broader range of health care professionals, consistent with the design of the Institute's PCMH model. It is interesting to note that although the proportion of patients with a primary care visit increased, the mean number of these visits per patient actually decreased as patients met with other members of the care team, including mental health professionals and diabetes educators. This redistribution of visits may allow for more efficient and effective care delivery.

Our stratified analysis of patients accessing care over the study period found a continual decrease in $\mathrm{HbA}_{1 \mathrm{c}}$ throughout the 8 years studied resulting in a total drop of nearly 2 percentage points among patients with high initial $\mathrm{HbA}_{1 \mathrm{c}}$ values (>9\%) and an increase of $0.34 \%$ among those starting with lower values $(\geq 9 \%)$. The small increase in $\mathrm{HbA}_{1 \mathrm{c}}$ values among the lower-risk group of patients is indicative of the difficulty in controlling this progressive disease, despite service enhancements.

This study has several limitations. It is a retrospective study that used data from EHRs recorded for purposes of care, rather than according to a strict research protocol; therefore, the details regarding some data (eg, purpose of a visit) are not clear. Similarly, visits and testing occurred according to a real-life rather 
than research schedule, meaning that follow-up $\mathrm{HbA}_{1 \mathrm{c}}$ values had the expected variability in timing. In examining use of services and clinical measures for each year, we opted to include all patients who received care, which meant that many patients were in the sample for multiple years. Analysis of comprehensive quality improvement projects like a PCMH effort is also limited as multiple components are implemented simultaneously, making it difficult to disentangle the impact of specific interventions..$^{10}$ Finally, we present unadjusted mean $\mathrm{HbA}_{1 \mathrm{c}}$ values for a subpopulation of patients. The impact of the practice transformation activities on the reduction in these values cannot be determined from this study as the trajectory of the decline was not determined for a control group. Observed changes could represent secular trends or regression to the mean. Further studies will be needed to determine if transition to a PCMH causes a more rapid decline in $\mathrm{HbA}_{1 \mathrm{c}}$ than would have occurred otherwise. Finally, it must be acknowledged that the findings may have been influenced by various contextual factors, described in the Supplemental Appendix (avail-

able online at http://annfammed.org/content/11/

קim Suppl_1/S68/suppl/DC1).

Despite these limitations, we believe that our study makes an important contribution to the PCMH literature by showing how a wide range of process changes can be made over a sustained period of time in the community health center setting. Our setting, a large FQHC network serving a diverse population, is unusual ${ }_{i}$ our sample size is large; and we were able to look at practice patterns-documented through an EHR_over an extended period of time. Over a 9-year transition period, this network implemented a series of practices changes, beginning with the implementation of an EHR system and the gradual introduction of new functions such as clinical decision supports, registries, and a patient portal. Noteworthy practice changes included the expansion and integration of psychosocial health services, the introduction of new staff such as CDEs, and role changes for current staff. In addition to enhanced outreach to patients, practices were also modified to target services to at-risk patients. We report on complex system change, including its component parts and the processes by which it was facilitated, including external funding, reimbursement incentives, and internal champions. Although we can- not conclude any causal relationship exists between practice transformation and reduced $\mathrm{HbA}_{1 \mathrm{c}}$ values because of a lack of a control group, diabetes control continued to improve throughout the study period.

To read or post commentaries in response to this article, see it online at http://www.annfammed.org/content/11/Suppl_1/S68.

Submitted July 2, 2012; submitted, revised, April 8, 2013; accepted April 9, 2013.

Key words: diabetes; patient-centered medical home; primary care; change, organizational; practice-based research; certification

Funding support: The study received support from the Agency for Healthcare Research and Quality, grant number R18HS019176.

Disclaimer: The content is solely the responsibility of the authors and does not necessarily represent the official views of the Agency for Healthcare Research and Quality.

\section{References}

1. Rittenhouse D, Shortell S. The patient-centered medical home: will it stand the test of health reform? JAMA. 2009;301(19) 2038-2040.

2. The Commonwealth Fund. Guiding transformation: how medical practices can become patient-centered medical homes. February 2012. http://www.commonwealthfund.org/ /media/Files/Publications/Fund\%20Report/2012/Feb/1582_Wagner_guiding_transformation_patientcentered_med_home_v2.pdf. Accessed May 18, 2012.

3. DeVoe JE, Fryer GE, Phillips R, Green L. Receipt of preventive care among adults: insurance status and usual source of care. Am J Public Health. 2003;93(5):786-791.

4. Roby DH, Kominski GF, Cameron ME. Improving access through health insurance coverage and safety net expansion: a review of the literature. Policy Brief (UCLA Center For Health Policy Research). 2007:1-6.

5. Starfield B, Shi L. The medical home, access to care, and insurance: a review of evidence. Pediatrics. 2004;113(5 Suppl):1493-1498.

6. Mainous AG, Koopman RJ, Gill JM, Baker R, Pearson WS. Relationship between continuity of care and diabetes control: evidence from the Third National Health and Nutrition Examination Survey. Am J Public Health. 2004;94(1):66-70.

7. Saultz JW, Albedaiwi W. Interpersonal continuity of care and patient satisfaction: a critical review. Ann Fam Med. 2004;2(5):445-451.

8. National Committee for Quality Assurance. PPC-PCMH Publications. http://www.ncqa.org/tabid/631/default.aspx. Accessed May 18, 2012.

9. UK Prospective Diabetes Study Group. Intensive blood-glucose control with sulphonylureas or insulin compared with conventional treatment and risk of complications in patients with type 2 diabetes (UKPDS: 33). Lancet. 1998;352(9131):837-853.

10. Walsh J, McDonald KM, Shojania KG, et al. Closing the Quality Gap: A Critical Analysis of Quality Improvement Strategies. Vol. 3: Hypertension Care. AHRQ Technical Reviews. Rockville, MD: Agency for Healthcare Research and Quality; 2005. Report 04-0051-3. 